\title{
Seasonal peak characteristic comparison analysis by hourly electricity demand model
}

\author{
Yusri Syam Akil ${ }^{1,}$, Hajime Miyauchi \\ ${ }^{1}$ Dept. of Electrical Engineering, Hasanuddin University, Makassar 90245, Indonesia \\ ${ }^{2}$ Dept. of Frontier Technology for Energy and Devices, Kumamoto University, Kumamoto 860-8555, Japan
}

Email address:

yusakil@yahoo.com (Y. S. Akil), miyauchi@cs.kumamoto-u.ac.jp (H. Miyauchi)

\section{To cite this article:}

Yusri Syam Akil, Hajime Miyauchi. Seasonal Peak Characteristic Comparison Analysis by Hourly Electricity Demand Model. International Journal of Energy and Power Engineering. Vol. 3, No. 3, 2014, pp. 132-138. doi: 10.11648/j.ijepe.20140303.14

\begin{abstract}
As driver variables may influence more than one area of electricity demand, knowing typical effect of the variables on certain demand areas is important. Utilities can use the information of managing power systems to meet electricity demand for different areas more effective. Based on the regression analysis approach, this study presents a peak demand characteristics comparison between Japanese residential and commercial areas in seasonal level by composing hourly electricity demand model for each area. Besides, a representative hour for off-peak demands is also analyzed. Similar variables (temperature, humidity, wind speed, and holidays) are applied to explain peak and off-peak of summer, autumn, winter, and spring in both areas. Results indicate key drivers for peak and off-peak demands are not same in the certain seasons for both areas. Obtained key variables tend to affect stronger peaks and off-peaks for residential than for commercial area in four observed seasons.
\end{abstract}

Keywords: Characteristics Comparison, Seasonal Peak, Hourly Demand Model, Residential Area, Commercial Area

\section{Introduction}

A demand driver refers to a variable which has large influence to the electricity consumption in one place. Though this driver variable may affect more than one area of electricity demand at the same time, its effect may not be same in each area. Basically, it is important to know typical effect of related variables on existing demand areas as it can be used in managing power systems particularly to meet electricity demands from different areas effectively. One of the methods that can be applied for the task is regression approach. From regression results of composed demand model, effect of considered variables on observed electricity demand can be known. Meteorological variables such as temperature, humidity, and/or rainfall are reported as demand drivers for residential area, commercial area, and/or a total area [1-6] in several different countries.

Because of daily electricity demand condition changes by time or has peak and off-peak hours generally (for example in residential or commercial area), it is meaningful to investigate typical effect of driver variables on such demand areas mainly during peak or maximum demand. An effective operation planning or other efforts to dealing with peak effectively are expected to be done as they may give benefits such as enhancement of system reliability and reduction of electricity cost [7].

This paper investigates the different contribution of the same key variables to seasonal peaks of two demand areas in Japan, namely residential and commercial areas. Besides, a representative hour for off-peak demand in both areas is also analyzed. Regression based hourly demand models [8] are used in this characteristics comparison study. Presented results may useful to manage power systems more effective especially to meet seasonal peaks (and off-peaks) from different areas in the same place.

Prior works on comparison of electricity demand can be found in [3, 9]. Reference [3] presented electricity demand analysis for Hong Kong context. In the study, demand for residential and commercial sectors correlated with climatic variables are analyzed by using principal component analysis (PCA). In [9], authors presented a methodology with indexes that can be used to identify pattern of electricity consumption. The authors analyzed and compared electricity load characteristic for Athens, Greece and London, UK which is correlated by temperature variable. 


\section{Typical Electricity Demands for Residential and Commercial Areas}

In this study, two demand areas in Japan, namely residential and commercial areas, are analyzed. Used data are historical demand in one city in Japan provided by a utility. Both data are normalized hourly demand data between June 2007 and December 2009. Similar variables namely three meteorological variables and holidays, are used to explain residential and commercial peak (and off-peak) demands. Meteorological data namely temperature $\mathrm{T}\left({ }^{\circ} \mathrm{C}\right)$, relative humidity RHD $(\%)$, and wind speed WDS $(\mathrm{m} / \mathrm{sec})$ are taken from website of Japan Meteorological Agency [10], meanwhile holidays data are from calendar.

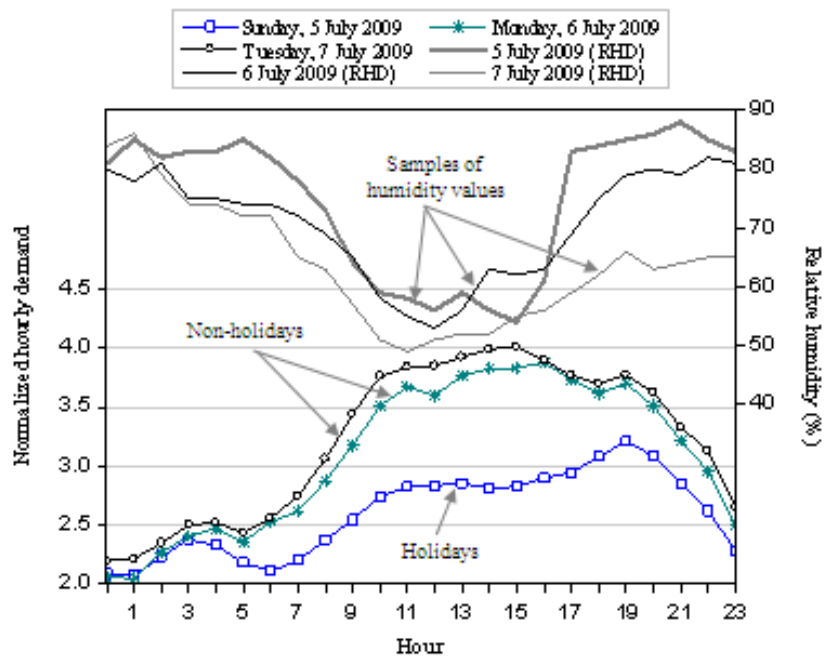

(a)

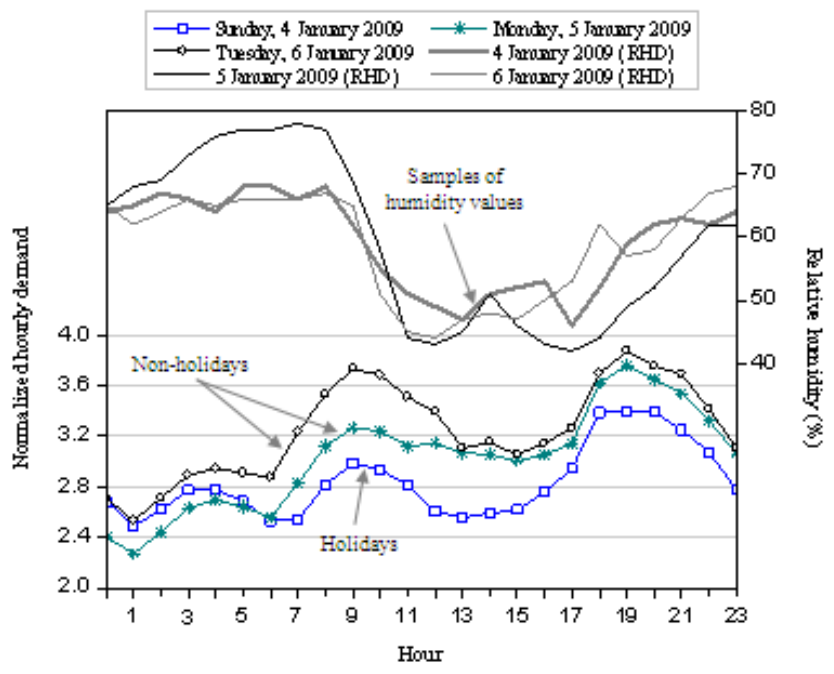

(b)

Figure 1. Samples of residential electricity demand values: (a) in summer (5 to 7 July 2009), (b) in winter (4 to 6 January 2009).

As an initial comparison analysis, Figs. 1 and 2 show samples of daily electricity load curves at the same day for residential and commercial areas, respectively. The loads are typical demands for three consecutive days under extreme temperature seasons (summer and winter) in year 2009. The residential demand is a total of three demand areas. Meanwhile, the commercial demand is a total of two areas. In Fig. 1, residential demand has peak and off-peak hours for both seasons. The pattern of daily demands tends similarly under the same season. However, the top of high demands for summer tends to be flat compared to winter. Demands are lower during holidays than non-holidays. For commercial area, typical demand on the observed days shows almost the same tendency with residential area as seen in Fig. 2.

However, variation of demand values in holidays and in non-holidays for the two areas are quite unique, and mainly under different seasons. Additionally, summer and winter periods in Japan are from June to August and from December to February, respectively. Meanwhile autumn is from September to November, and spring is from March to May. Naturally, November month is dominated by cold temperature and on the contrary in May.

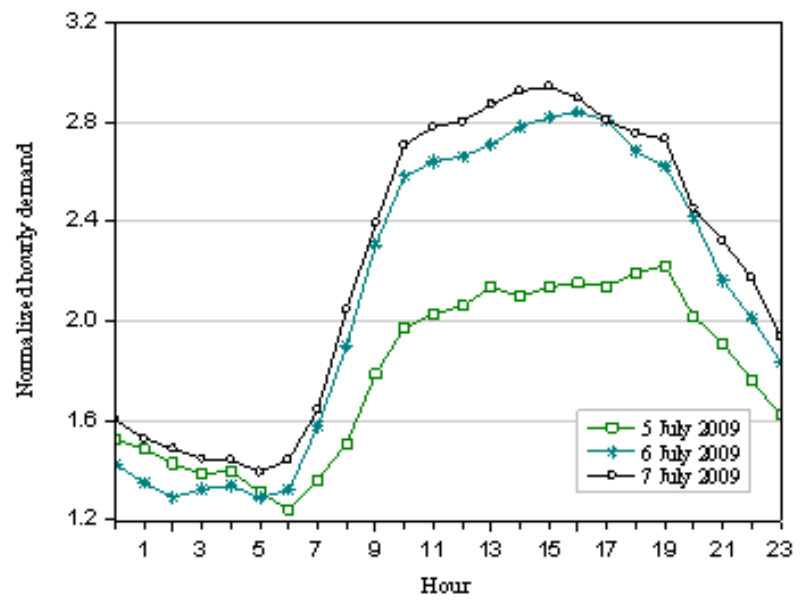

(a)

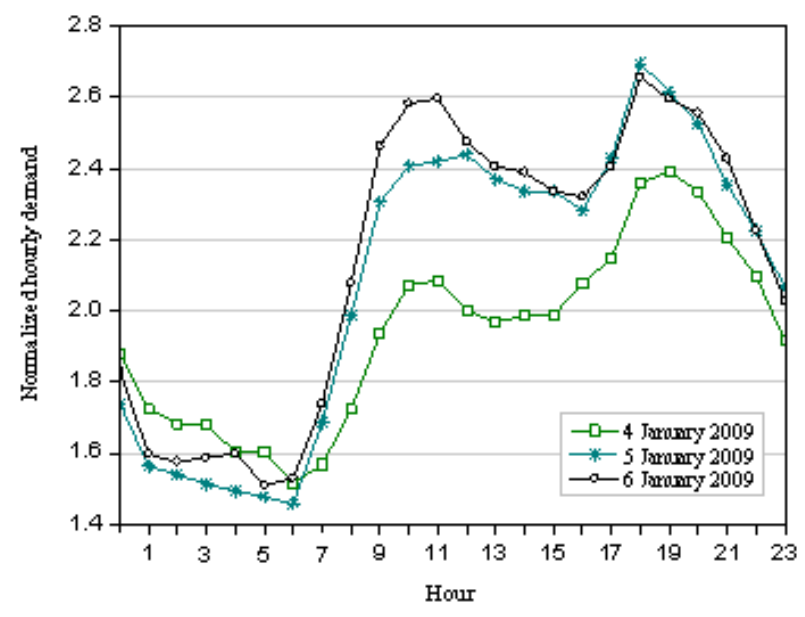

(b)

Figure 2. Samples of commercial electricity demand values: (a) in summer (5 to 7 July 2009), (b) in winter (4 to 6 January 2009) 


\section{Hourly Electricity Demand Models for Peak Characteristics Comparison}

\subsection{Seasonal Peak for Residential and Commercial Areas}

Based on demand data, peak hours for residential and commercial area in each season are shown in Table 1. Besides, a representative off-peak demand for each season is also given. The peaks are the biggest value among hourly demand in each season in the period of June 2007 to December 2009 for each area. Obtained peaks under hot seasons (summer and autumn) are in daytime, and under cold seasons (winter and spring) are in evening. High temperature condition in daytime under hot seasons (mainly in summer), and severe low temperature in evening under cold seasons (mainly in winter) contribute to the situation as extensive use of cooling/heating equipments is needed in the related period in each area. Following the peaks time, off-peaks representative for hot seasons and cold seasons are also demands in daytime and in evening namely at 09:00 and 21:00, respectively. From Table 1, most of the peaks for residential and commercial areas occur in the different hours. Among them, only peak in spring occurs at the same hour. This is initially indicated the uniqueness of seasonal (peak) characteristics for each area. Variation of the biggest demand values in each hour for both areas in studied period is shown in Fig. 3.

Table 1. Comparison of peak time for residential and commercial areas in each season, and a representative time for off-peak

\begin{tabular}{llll}
\multicolumn{1}{c}{ Residential Area } & \multicolumn{2}{c}{ Commercial Area } \\
\hline Peak and Off-Peak & Hour & Peak and Off-Peak & Hour \\
\hline Summer peak & $15: 00$ & Summer peak & $16: 00$ \\
Autumn peak & $15: 00$ & Autumn peak & $17: 00$ \\
Winter peak & $19: 00$ & Winter peak & $18: 00$ \\
Spring peak & $19: 00$ & Spring peak & $19: 00$ \\
Summer off-peak & $09: 00$ & Summer off-peak & $09: 00$ \\
Autumn off-peak & $09: 00$ & Autumn off-peak & $09: 00$ \\
Winter off-peak & $21: 00$ & Winter off-peak & $21: 00$ \\
Spring off-peak & $21: 00$ & Spring off-peak & $21: 00$ \\
\hline
\end{tabular}

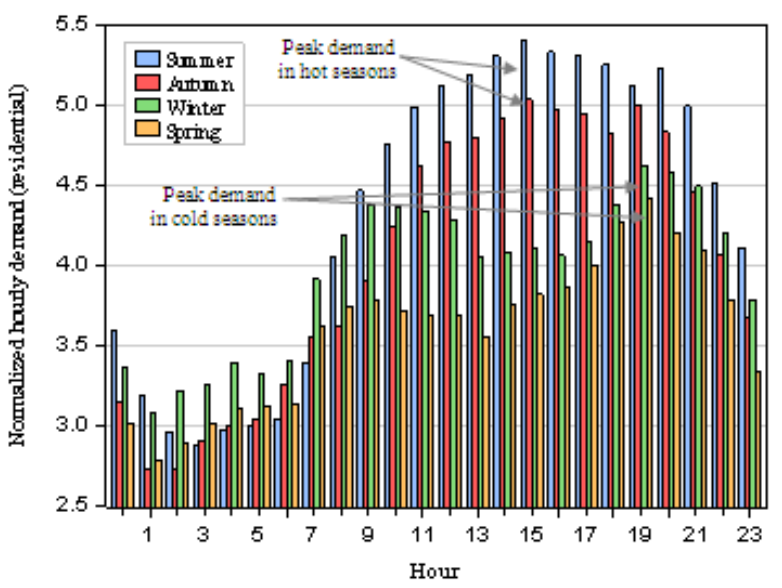

(a)

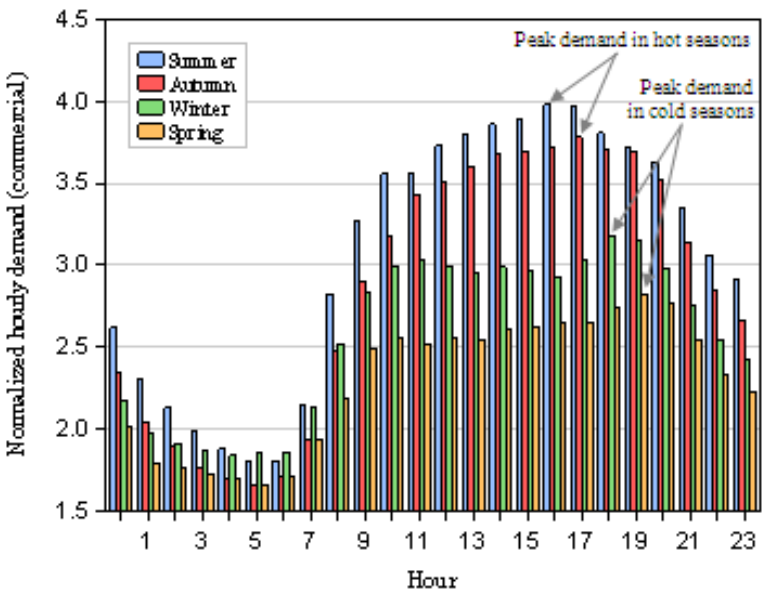

(b)

Figure 3. Biggest seasonal electricity demand value for each hour: (a) residential area, (b) commercial area.

\subsection{Peak and Off-Peak Models for Residential and Commercial Areas in Each Season}

From Table 1, hourly peak and off-peak demand models for residential and commercial areas are composed for comparison analysis. Applied variables in the hourly models especially for temperature variables (CDD and/or HDD) are based on the temperature condition in each season [8]. As extended from paper [8], some new analyses are presented in this study including introducing a new variable (wind speed) in the developed models with focus on the seasonal peak and off-peak characteristics comparison between observed electricity demand areas.

Hourly model equations of the residential peak demand (PD) of each season are given as follows.

$$
\begin{aligned}
R s m P D_{15} & =\alpha_{0}+\alpha_{1} C D D+\alpha_{2} R H D+\alpha_{3} W D S \\
& +\alpha_{4} D H+u_{t} \\
R a P D_{15} & =\alpha_{0}+\alpha_{1} C D D+\alpha_{2} H D D+\alpha_{3} R H D \\
& +\alpha_{4} W D S+\alpha_{5} D H+u_{t}
\end{aligned}
$$




$$
\begin{aligned}
R w P D_{15} & =\alpha_{0}+\alpha_{1} H D D+\alpha_{2} R H D+\alpha_{3} W D S \\
& +\alpha_{4} D H+u_{t} \\
R s P D_{19}= & \alpha_{0}+\alpha_{1} C D D+\alpha_{2} H D D+\alpha_{3} R H D \\
& +\alpha_{4} W D S+\alpha_{5} D H+u_{t}
\end{aligned}
$$

$R s m P D_{15}, R a P D_{15}, R w P D_{19}$, and $R s P D_{19}$ in (1)-(4) are peak in summer, autumn, winter, and spring season for residential area, respectively. Subscript in each name of model shows the hour of peak in the related seasons. $\alpha_{0}$ is an intercept value and $\alpha_{1}, \alpha_{2}, \alpha_{3}, \alpha_{4}, \alpha_{5}$ are regression coefficient values. $u_{t}$ is error term of models. $C D D$ and HDD are cooling degree days and heating degree days $(\mathrm{HDD}=$ $\max \left(\mathrm{T}_{\text {ref1 }}-\mathrm{T}, 0\right)$, and $\left.\mathrm{CDD}=\max \left(\mathrm{T}-\mathrm{T}_{\mathrm{ref} 2}, 0\right)\right)[1,5,9] . D H$ is a dummy for holidays which has value 1 when weekends and holidays, and 0 otherwise. For equations of off-peak demand (OPD) models, they are similar to PD models (1)-(4). As reference value of temperature $\left(\mathrm{T}_{\text {ref }}=\mathrm{T}_{\text {ref1 }}=\mathrm{T}_{\text {ref2 } 2}\right)$ for $C D D$ and $H D D$ in all models, $18{ }^{\circ} \mathrm{C}$ is used. To reduce autocorrelation, the common method namely incorporating autoregressive in the error term of models is used [11]. We test until order two in each hourly model, and select the best one based on the smallest values of Akaike Information Criterion (AIC) [1,5] and the biggest value of adjusted coefficient of determination $\left(\mathrm{R}^{2}\right)$ of model. Next, for commercial area, PD and OPD models in each season are the same as models for residential area. Letter $C$ is used as an initial name for models in the area.

\section{Results and Analysis}

Tables 2 and 3 present best regression results of hourly PD and OPD models for summer, autumn, winter, and spring for residential area. Meanwhile, Tables 4 and 5 present results for commercial area. Best models are specified by autoregressive order two excluding $\mathrm{CwOPD}_{21}$ which is specified with autoregressive order one. The 16 composed hourly models are validated well. Durbin-Watson statistics values $D-W$ are near 2, indicating the absence of autocorrelation in models. Besides, at least one of the applied variables in each composed model influence related PD and OPD in both areas as indicated by Prob. (F-Statistic) values are 0. For handling heteroskedasticity, corrected standard error regression is performed [11]. All reported results in this paper are computed by EViews 6 [12].

From results, seasonal PD and OPD characteristics for residential and commercial areas can be explained and compared as follows.

\subsection{Demand for Residential Area}

From Tables 2 and 3, the $R^{2}$, values of models for residential area are around $80.71 \%$ to $88.84 \%$ for PD, and $80.47 \%$ to $85.45 \%$ for OPD which indicating the composed models have fairly good fitness degree. At $5 \%$ significance level of $p$-value, $C D D$ and $H D D$ have significance in models as indicated by their $p$-values. For $R H D$ variable, it has significance in all models excluding $R H D$ in winter for PD $\left(\mathrm{RwPD}_{19}\right)$ and $R H D$ in spring for OPD $\left(\mathrm{RsOPD}_{21}\right)$. Low relatively values for humidity during cold periods may contribute to the situation. Meanwhile $W D S$ variable has significance only in autumn for $\mathrm{PD}\left(\mathrm{RaPD}_{15}\right)$ and in summer for OPD $\left(\mathrm{RsmOPD}_{09}\right)$. Particularly for $C D D, H D D, R H D$, and $D H$ variables, the significance of almost these variables in models confirmed that they are important/key variables in influencing PD and OPD residential area. For intercept values $\left(\alpha_{0}\right.$ and $\left.\hat{\alpha}_{0}\right)$ which represent base demand, it is found highest in winter compared to other three seasons. Utilization more lighting during winter (daylight is only about 10.5 hours) which contributes to base demand, may relate to the situation. Base demands at peak hour are higher than off-peak in each season. Comparing meteorological variables, $C D D$ and $H D D$ give the largest effect to demands, and in contrast for $W D S$ generally. The highest coefficient for $C D D$ and $H D D$ are obtained in autumn, namely PD at 15:00 (0.0889) and OPD at 09:00 (0.0478), respectively. For RHD, summer model has highest coefficient of this variable with value 0.0096 for PD at 15:00, and 0.0124 for OPD at 09:00. This indicates humidity has highest influence to summer peak and off-peak. In Japan, humidity variation is high during hot seasons and especially in July. For $W D S$, the highest influence of this variable is obtained in autumn for PD at 15:00 (0.0155) and in summer for OPD in the morning at 09:00 (-0.0178). Wind speed is sometime high within hot seasons and mainly in autumn. Regarding $D H$, residential demand (PD and OPD) will decrease in all seasons. However, the highest effect of holidays is obtained in summer and on the contrary in spring.

\subsection{Demand for Commercial Area}

Obtained $R^{2}$, values for commercial area are around $70.08 \%$ to $86.69 \%$ and $76.82 \%$ to $86.32 \%$ for PD and OPD models, respectively as seen in Tables 4 and 5 . All composed hourly models have fairly good fitness degree. $C D D$ and $H D D$ have significance at 5\% significance level in models except for $H D D$ in autumn for $\mathrm{PD}\left(\mathrm{CaPD}_{17}\right)$ and $\mathrm{OPD}$ $\left(\mathrm{CaOPD}_{09}\right)$. Meanwhile $R H D$ has significance in all models excluding in winter PD model $\left(\mathrm{CwPD}_{18}\right)$. For $W D S$, it has significance only in autumn for $\mathrm{PD}\left(\mathrm{CaPD}_{17}\right)$. This confirmed that from implemented meteorological variables, $C D D, H D D$, and $R H D$ are main drivers for commercial area generally. From obtained $\beta_{0}$ and $\hat{\beta}_{0}$ values, seasonal base demand is highest in winter. Base demands tend to high during peaks rather than off-peaks for each season. Among meteorological variables, $C D D$ and $H D D$ have highest effect on PD and OPD in each season as indicated by their regression coefficients. However, coefficient of $C D D$ (0.0704) is obtained highest in summer PD at 16:00 and $H D D(0.0274)$ is highest in winter PD at 18:00. For humidity, the highest effect on demands is found in summer with coefficient value 0.0083 for PD at 16:00 and 0.0081 for OPD at 09:00. Meanwhile for $W D S$ is in autumn PD at 17:00 with coefficient value is 0.0155 . Holidays $D H$ will cause 
commercial PD and OPD decrease in all seasons (as business activities are small during holidays period), and largely in summer.

\subsection{Seasonal PD and OPD Characteristics Comparison}

\subsubsection{Summer Period}

In severe hot temperature period, $R^{2}$, values of models are larger for commercial than residential. It means, applied variables can explain summer PD and OPD better in commercial than in residential area. However, the values of $R^{2}$ ' for both areas are higher for PD than OPD. Summer base demands are relatively larger for residential than commercial area. Likewise with regression coefficient values for significance meteorological variables, they are obtained larger for residential than commercial area. It confirms variables influence residential demands higher. As utilization of cooling equipments needs cost, residential consumers are more flexible to use air-conditioner in the observed PD and OPD hour than commercial consumers. $C D D$ has larger effect to PD and OPD in each area than $R H D$ and $W D S$ variables. This confirmed $C D D$ is the most significance meteorological variable for summer electricity demands. About holidays, residential area is influenced much by this variable and mainly for PD.

\subsubsection{Autumn and Spring Periods}

In non-severe temperature periods, applied variables can explain demands better in residential than commercial area excluding OPD in autumn as shown by $R^{2}$, values. However, for residential area, the $R^{2}$, is higher for PD than OPD in autumn, and in contrast in spring. Meanwhile for commercial area, the $R^{2}$, is higher for PD than OPD in both seasons. Under the same season, base demands are larger for residential than commercial area. Coefficient values of meteorological variables are larger for residential than commercial area indicating applied variables affect higher residential demands (in autumn and in spring) than commercial demands. This represents attitude of residential consumers which is more flexible in using heating and cooling equipments in the related season than commercial consumers. As in these periods two temperature variables (CDD and HDD) are considered, they have larger effect to PD and OPD in each area than RHD and $W D S$ variables excluding in $\mathrm{CaPD}_{17}$ and $\mathrm{CaOPD}_{09}$ as $H D D$ is not significant in the models. Holidays make autumn and spring electricity demands lower and mainly for residential area.

Table 2. Results of hourly PD models for residential area

\begin{tabular}{|c|c|c|c|c|c|c|c|c|}
\hline \multirow[b]{2}{*}{ Explanation Variable } & \multicolumn{2}{|c|}{$\operatorname{RsmPD}_{15}$} & \multicolumn{2}{|c|}{$\operatorname{RaPD}_{15}$} & \multicolumn{2}{|c|}{ RwPD $_{19}$} & \multicolumn{2}{|c|}{ RsPD $_{19}$} \\
\hline & Coef. & $\begin{array}{c}\text { Prob. } \\
(p \text {-value })\end{array}$ & Coef. & $\begin{array}{c}\text { Prob. } \\
(p-v a l u e)\end{array}$ & Coef. & $\begin{array}{c}\text { Prob. } \\
\text { (p-value })\end{array}$ & Coef. & $\begin{array}{c}\text { Prob. } \\
(p-v a l u e)\end{array}$ \\
\hline \multirow[b]{2}{*}{$\alpha_{0}$} & 2.6964 & 0 & 2.3880 & 0 & 3.5268 & 0 & 2.7606 & 0 \\
\hline & $(7.48)$ & $0.3603^{*}$ & $(21.55)$ & $0.1108^{*}$ & $(44.11)$ & $0.0799 *$ & $(34.52)$ & $0.0799 *$ \\
\hline \multirow{2}{*}{ CDD } & 0.0813 & 0 & 0.0889 & 0 & & & 0.0400 & 0 \\
\hline & $(6.60)$ & $0.0123 *$ & $(10.06)$ & $0.0088^{*}$ & & & $(6.79)$ & $0.0058^{*}$ \\
\hline \multirow{2}{*}{ HDD } & & & 0.0211 & 0.0353 & 0.0437 & 0 & 0.0357 & 0 \\
\hline & & & $(2.11)$ & $0.0100 *$ & $(9.49)$ & $0.0046^{*}$ & $(5.11)$ & $0.0070^{*}$ \\
\hline \multirow{2}{*}{ RHD } & 0.0096 & 0.0007 & 0.0084 & 0 & -0.0008 & $\underline{0.2307}$ & 0.0037 & 0 \\
\hline & $(3.42)$ & $0.0028 *$ & $(7.86)$ & $0.0010^{*}$ & $(-1.20)$ & $0.0007 *$ & $(5.37)$ & $0.0006^{*}$ \\
\hline \multirow{2}{*}{ WDS } & 0.0105 & $\underline{0.3140}$ & 0.0155 & 0.0493 & -0.0005 & $\underline{0.9349}$ & 0.0034 & $\underline{0.6606}$ \\
\hline & $(1.00)$ & $\overline{0.0104 *}$ & $(1.97)$ & $0.0078^{*}$ & $(-0.08)$ & $\overline{0.0066^{*}}$ & $(0.43)$ & $\overline{0.0077 *}$ \\
\hline \multirow{2}{*}{$\mathrm{DH}$} & -0.6741 & 0 & -0.5566 & 0 & -0.3770 & 0 & -0.3132 & 0 \\
\hline & $(-20.88)$ & $0.0322 *$ & $(-21.40)$ & $0.0260^{*}$ & $(-16.30)$ & $0.0231 *$ & $(-17.95)$ & $0.0174 *$ \\
\hline \multicolumn{9}{|c|}{ Regression Statistics } \\
\hline $\mathrm{R}^{2^{\prime}}$ & \multicolumn{2}{|c|}{0.8621} & \multicolumn{2}{|c|}{0.8884} & \multicolumn{2}{|c|}{0.8071} & \multicolumn{2}{|c|}{0.8477} \\
\hline D-W & \multicolumn{2}{|c|}{2.0604} & \multicolumn{2}{|c|}{2.1096} & \multicolumn{2}{|c|}{1.9741} & \multicolumn{2}{|c|}{2.0968} \\
\hline SE Regression & \multicolumn{2}{|c|}{0.2655} & \multicolumn{2}{|c|}{0.2244} & \multicolumn{2}{|c|}{0.1469} & \multicolumn{2}{|c|}{0.1278} \\
\hline Prob. (F-Statistic) & \multicolumn{2}{|c|}{0.0000} & \multicolumn{2}{|c|}{0.0000} & \multicolumn{2}{|c|}{0.0000} & \multicolumn{2}{|c|}{0.0000} \\
\hline $\mathrm{AIC}$ & \multicolumn{2}{|c|}{0.2109} & \multicolumn{2}{|c|}{-0.1209} & \multicolumn{2}{|c|}{-0.9645} & \multicolumn{2}{|c|}{-1.2323} \\
\hline
\end{tabular}

Notes: () t-statistic; *adjs. standard error; not significant variable, SE Regression is standard error of regression (similar for Tables 3, 4, and 5)

Table 3. Results of hourly OPD models for residential area

\begin{tabular}{|c|c|c|c|c|c|c|c|c|}
\hline \multirow[b]{2}{*}{ Explanation Variable } & \multicolumn{2}{|c|}{ RsmOPD $_{09}$} & \multicolumn{2}{|c|}{$\mathrm{RaOPD}_{09}$} & \multicolumn{2}{|c|}{$\mathrm{RwOPD}_{21}$} & \multicolumn{2}{|c|}{$\mathrm{RsOPD}_{21}$} \\
\hline & Coef. & $\begin{array}{c}\text { Prob. } \\
(p \text {-value })\end{array}$ & Coef. & $\begin{array}{c}\text { Prob. } \\
(p-v a l u e)\end{array}$ & Coef. & $\begin{array}{c}\text { Prob. } \\
(p \text {-value })\end{array}$ & Coef. & $\begin{array}{c}\text { Prob. } \\
(p \text {-value })\end{array}$ \\
\hline \multirow{2}{*}{$\hat{\alpha}_{0}$} & 1.9607 & 0 & 2.3483 & 0 & 3.3951 & 0 & 2.9053 & 0 \\
\hline & (13.86) & $0.1414^{*}$ & $(27.48)$ & $0.0854 *$ & $(41.86)$ & $0.0810^{*}$ & (49.28) & $0.0589 *$ \\
\hline \multirow{2}{*}{ CDD } & 0.0785 & 0 & 0.0603 & 0 & & & 0.0205 & 0 \\
\hline & (10.56) & $0.0074 *$ & $(8.03)$ & $0.0075^{*}$ & & & $(4.31)$ & $0.0047^{*}$ \\
\hline HDD & & & 0.0478 & 0 & 0.0449 & 0 & 0.0329 & 0 \\
\hline
\end{tabular}




\begin{tabular}{|c|c|c|c|c|c|c|c|c|}
\hline \multirow[b]{2}{*}{ Explanation Variable } & \multicolumn{2}{|c|}{ RsmOPD $_{09}$} & \multicolumn{2}{|c|}{$\mathrm{RaOPD}_{09}$} & \multicolumn{2}{|c|}{$\mathrm{RwOPD}_{21}$} & \multicolumn{2}{|c|}{ RsOPD $_{21}$} \\
\hline & Coef. & $\begin{array}{c}\text { Prob. } \\
\text { (p-value) }\end{array}$ & Coef. & $\begin{array}{c}\text { Prob. } \\
(p-v a l u e)\end{array}$ & Coef. & $\begin{array}{c}\text { Prob. } \\
\text { (p-value) }\end{array}$ & Coef. & $\begin{array}{c}\text { Prob. } \\
\text { (p-value) }\end{array}$ \\
\hline \multirow{3}{*}{ RHD } & & & $(4.91)$ & $0.0097 *$ & $(11.86)$ & $0.0037^{*}$ & (5.43) & $0.0060^{*}$ \\
\hline & 0.0124 & 0 & 0.0051 & 0 & -0.0020 & 0.0034 & 0.0008 & $\underline{0.1871}$ \\
\hline & $(9.88)$ & $0.0012 *$ & $(5.06)$ & $0.0010^{*}$ & $(-2.96)$ & $0.0006^{*}$ & $(1.32)$ & $0.0006^{*}$ \\
\hline WDS & $\begin{array}{c}-0.0178 \\
(-2.49)\end{array}$ & $\begin{array}{c}0.0131 \\
0.0071 *\end{array}$ & $\begin{array}{c}0.0108 \\
(1.41)\end{array}$ & $\frac{0.1585}{0.0076^{*}}$ & $\begin{array}{l}-0.0041 \\
(-0.71)\end{array}$ & $\frac{0.4775}{0.0057^{*}}$ & $\begin{array}{c}-0.0068 \\
(-0.98)\end{array}$ & $\frac{0.3271}{0.0069^{*}}$ \\
\hline \multirow[t]{2}{*}{ DH } & $\begin{array}{l}-0.5606 \\
(-23.22)\end{array}$ & $\begin{array}{c}0 \\
0.0241 *\end{array}$ & $\begin{array}{l}-0.4931 \\
(-23.84)\end{array}$ & $\begin{array}{c}0 \\
0.0206^{*}\end{array}$ & $\begin{array}{l}-0.2860 \\
(-12.95)\end{array}$ & $\begin{array}{c}0 \\
0.0220^{*}\end{array}$ & $\begin{array}{l}-0.2483 \\
(-15.73)\end{array}$ & $\begin{array}{c}0 \\
0.0157^{*}\end{array}$ \\
\hline & \multicolumn{6}{|c|}{$\begin{array}{l}0.0200 \\
\text { Regression Statistics }\end{array}$} & & \\
\hline $\mathrm{R}^{2^{\prime}}$ & \multicolumn{2}{|c|}{0.8485} & \multicolumn{2}{|c|}{0.8137} & \multicolumn{2}{|c|}{0.8047} & \multicolumn{2}{|c|}{0.8545} \\
\hline $\mathrm{D}-\mathrm{W}$ & \multicolumn{2}{|c|}{2.0697} & \multicolumn{2}{|c|}{2.0997} & \multicolumn{2}{|c|}{1.9918} & \multicolumn{2}{|c|}{2.0458} \\
\hline SE Regression & \multicolumn{2}{|c|}{0.1978} & \multicolumn{2}{|c|}{0.1754} & \multicolumn{2}{|c|}{0.1404} & \multicolumn{2}{|c|}{0.1080} \\
\hline Prob. (F-Statistic) & \multicolumn{2}{|c|}{0.0000} & \multicolumn{2}{|c|}{0.0000} & \multicolumn{2}{|c|}{0.0000} & \multicolumn{2}{|c|}{0.0000} \\
\hline AIC & \multicolumn{2}{|c|}{-0.3771} & \multicolumn{2}{|c|}{-0.6136} & \multicolumn{2}{|c|}{-1.0557} & \multicolumn{2}{|c|}{-1.5693} \\
\hline
\end{tabular}

Table 4. Results of hourly PD models for commercial area

\begin{tabular}{|c|c|c|c|c|c|c|c|c|}
\hline \multirow[b]{2}{*}{ Explanation Variable } & \multicolumn{2}{|c|}{ CsmPD $_{16}$} & \multicolumn{2}{|c|}{$\mathrm{CaPD}_{17}$} & \multicolumn{2}{|c|}{$\mathrm{CwPD}_{18}$} & \multicolumn{2}{|c|}{$\mathrm{CsPD}_{19}$} \\
\hline & Coef. & $\begin{array}{c}\text { Prob. } \\
\text { (p-value })\end{array}$ & Coef. & $\begin{array}{c}\text { Prob. } \\
(p-v a l u e)\end{array}$ & Coef. & $\begin{array}{c}\text { Prob. } \\
(p-v a l u e)\end{array}$ & Coef. & $\begin{array}{c}\begin{array}{c}\text { Prob. } \\
(p-v a l u e)\end{array} \\
\end{array}$ \\
\hline \multirow{2}{*}{$\beta_{0}$} & 1.7772 & 0 & 1.8364 & 0 & 2.3333 & 0 & 1.8897 & 0 \\
\hline & $(6.55)$ & $0.2709^{*}$ & (19.10) & $0.0961 *$ & $(34.50)$ & $0.0676^{*}$ & $(36.71)$ & $0.0514 *$ \\
\hline \multirow{2}{*}{ CDD } & 0.0704 & 0 & 0.0678 & 0 & & & 0.0329 & 0 \\
\hline & $(7.43)$ & $0.0094 *$ & $(6.75)$ & $0.0100^{*}$ & & & $(5.77)$ & $0.0057^{*}$ \\
\hline \multirow{2}{*}{ HDD } & & & 0.0100 & $\underline{0.2697}$ & 0.0274 & 0 & 0.0174 & 0.0009 \\
\hline & & & $(1.10)$ & $0.0090^{*}$ & $(5.74)$ & $0.0047 *$ & $(3.36)$ & $0.0051^{*}$ \\
\hline \multirow{2}{*}{ RHD } & 0.0083 & 0.0002 & 0.0042 & 0 & 0.0004 & $\underline{0.5786}$ & 0.0026 & 0 \\
\hline & $(3.72)$ & $0.0022 *$ & $(4.19)$ & $0.0010^{*}$ & $(0.55)$ & $0.0007^{*}$ & $(5.27)$ & $0.0005^{*}$ \\
\hline \multirow{2}{*}{ WDS } & 0.0173 & $\underline{0.0581}$ & 0.0155 & 0.0108 & -0.0021 & $\underline{0.7733}$ & 0.0034 & $\underline{0.5895}$ \\
\hline & $(1.90)$ & $0.0090^{*}$ & $(2.56)$ & $0.0060^{*}$ & $(-0.28)$ & $0.0075^{*}$ & $(0.54)$ & $0.0064^{*}$ \\
\hline \multirow{2}{*}{ DH } & -0.4729 & 0 & -0.3092 & 0 & -0.2979 & 0 & -0.1956 & 0 \\
\hline & $(-18.13)$ & $0.0260^{*}$ & $(-13.32)$ & $0.0232 *$ & $(-13.54)$ & $0.0219^{*}$ & $(-15.18)$ & $0.0128 *$ \\
\hline \multicolumn{9}{|c|}{ Regression Statistics } \\
\hline $\mathrm{R}^{2^{\prime}}$ & \multicolumn{2}{|c|}{0.8669} & \multicolumn{2}{|c|}{0.8519} & \multicolumn{2}{|c|}{0.7008} & \multicolumn{2}{|c|}{0.7891} \\
\hline D-W & \multicolumn{2}{|c|}{2.1120} & \multicolumn{2}{|c|}{2.0292} & \multicolumn{2}{|c|}{1.9493} & \multicolumn{2}{|c|}{1.9541} \\
\hline SE Regression & \multicolumn{2}{|c|}{0.1902} & \multicolumn{2}{|c|}{0.1946} & \multicolumn{2}{|c|}{0.1432} & \multicolumn{2}{|c|}{0.0890} \\
\hline Prob. (F-Statistic) & \multicolumn{2}{|c|}{0.0000} & \multicolumn{2}{|c|}{0.0000} & \multicolumn{2}{|c|}{0.0000} & \multicolumn{2}{|c|}{0.0000} \\
\hline $\mathrm{SC}$ & \multicolumn{2}{|c|}{-0.4554} & \multicolumn{2}{|c|}{-0.4061} & \multicolumn{2}{|c|}{-1.0151} & \multicolumn{2}{|c|}{-1.9566} \\
\hline
\end{tabular}

Table 5. Results of hourly OPD models for commercial area

\begin{tabular}{|c|c|c|c|c|c|c|c|c|}
\hline \multirow[b]{2}{*}{ Explanation Variable } & \multicolumn{2}{|c|}{ CsmOPD $_{09}$} & \multicolumn{2}{|c|}{$\mathrm{CaOPD}_{09}$} & \multicolumn{2}{|c|}{ CwOPD $_{21}$} & \multicolumn{2}{|c|}{$\mathrm{CsOPD}_{21}$} \\
\hline & Coef. & $\begin{array}{c}\text { Prob. } \\
(p-\text { value })\end{array}$ & Coef. & $\begin{array}{c}\text { Prob. } \\
(p-\text { value })\end{array}$ & Coef. & $\begin{array}{c}\text { Prob. } \\
\text { (p-value })\end{array}$ & Coef. & $\begin{array}{c}\text { Prob. } \\
\text { (p-value) }\end{array}$ \\
\hline \multirow{2}{*}{$\hat{\beta}_{0}$} & 1.3804 & 0 & 1.5995 & 0 & 2.1762 & 0 & 1.8421 & 0 \\
\hline & $(10.35)$ & $0.1333^{*}$ & $(21.29)$ & $0.0750^{*}$ & (38.34) & $0.0567 *$ & $(45.89)$ & $0.0401 *$ \\
\hline \multirow{2}{*}{$\mathrm{CDD}$} & 0.0566 & 0 & 0.0428 & 0 & & & 0.0199 & 0.0010 \\
\hline & $(9.36)$ & $0.0060^{*}$ & $(5.43)$ & $0.0078 *$ & & & $(3.35)$ & $0.0059 *$ \\
\hline HDD & & & $\begin{array}{l}0.0097 \\
(1.13)\end{array}$ & $\underline{\underline{0.2564}}$ & $\begin{array}{c}0.0264 \\
(9.34)\end{array}$ & $\begin{array}{c}0 \\
0.0028 *\end{array}$ & $\begin{array}{l}0.0151 \\
(3.99)\end{array}$ & $\begin{array}{c}0.0001 \\
0.0038^{*}\end{array}$ \\
\hline \multirow{2}{*}{ RHD } & 0.0081 & 0 & 0.0024 & 0.0006 & -0.0015 & 0.0042 & 0.0009 & 0.0363 \\
\hline & $(7.66)$ & $0.0010^{*}$ & $(3.46)$ & $0.0007^{*}$ & $(-2.89)$ & $0.0005^{*}$ & $(2.11)$ & $0.0004^{*}$ \\
\hline \multirow{2}{*}{ WDS } & -0.0104 & $\underline{0.0556}$ & 0.0093 & $\underline{0.0515}$ & -0.0038 & $\underline{0.3470}$ & 0.0049 & $\underline{0.3250}$ \\
\hline & $(-1.92)$ & $0.0054 *$ & $(1.95)$ & $0.0047 *$ & $(-0.94)$ & $0.0041 *$ & $(0.98)$ & $0.0050^{*}$ \\
\hline \multirow{2}{*}{ DH } & -0.4122 & 0 & -0.2921 & 0 & -0.1260 & 0 & -0.1291 & 0 \\
\hline & $(-21.23)$ & $0.0194 *$ & $(-16.80)$ & $0.0173 *$ & $(-7.55)$ & $0.0166^{*}$ & $(-11.25)$ & $0.0114^{*}$ \\
\hline \multicolumn{9}{|c|}{ Regression Statistics } \\
\hline $\mathrm{R}^{2}$ & \multicolumn{2}{|c|}{0.8632} & \multicolumn{2}{|c|}{0.8474} & \multicolumn{2}{|c|}{0.7682} & \multicolumn{2}{|c|}{0.7759} \\
\hline $\mathrm{D}-\mathrm{W}$ & \multicolumn{2}{|c|}{2.0798} & \multicolumn{2}{|c|}{2.0358} & \multicolumn{2}{|c|}{2.0890} & \multicolumn{2}{|c|}{1.9609} \\
\hline SE Regression & \multicolumn{2}{|c|}{0.1531} & \multicolumn{2}{|c|}{0.1346} & \multicolumn{2}{|c|}{0.1028} & \multicolumn{2}{|c|}{0.0746} \\
\hline Prob. (F-Statistic) & \multicolumn{2}{|c|}{0.0000} & \multicolumn{2}{|c|}{0.0000} & \multicolumn{2}{|c|}{0.0000} & \multicolumn{2}{|c|}{0.0000} \\
\hline AIC & \multicolumn{2}{|c|}{-0.8900} & \multicolumn{2}{|c|}{-1.1426} & \multicolumn{2}{|c|}{-1.6822} & \multicolumn{2}{|c|}{-2.3084} \\
\hline
\end{tabular}




\subsubsection{Winter Period}

In severe cold temperature period, $R^{2}$, values of models are larger for residential than commercial area which indicates variables can explain residential demand better. The $R^{2}$, values tend to higher for OPD than $\mathrm{PD}$ in residential and on the contrary in commercial area. For base demands, they are obtained larger in residential than commercial area and mainly for PD. The influence of significance meteorological variables (HDD in PD models, and HDD and RHD in OPD models) are higher in residential than commercial area. As in other seasons, residential consumers show similar attitude in winter concerning utilization of heating equipments (electric heater). In winter case, $H D D$ is most significance variable, meanwhile $R H D$ and $W D S$ tend not to have significance in models generally. Next, holidays in winter will reduce demands mainly for PD of residential area.

\section{Conclusions}

In this paper, a peak demand characteristics comparison analysis between residential and commercial areas in Japan is presented. Besides, an off-peak demand comparison analysis is also provided. By using regression approach, similar variables namely temperature, humidity, wind speed, and holidays are applied to explain demands with intention to investigate typical effect of the variables on seasonal peaks (PD) and off-peaks (OPD) in each area. Hourly electricity PD and OPD models for summer, autumn, winter, and spring period are composed to achieve the aim. It is obtained that most of the seasonal peaks for residential and commercial areas occurred in the different hours. The values of adjusted coefficient of determination $R^{2}$ of PD are around $80.71 \%$ to $88.84 \%$ for residential and around $70.08 \%$ to $86.69 \%$ for commercial area. Meanwhile for OPD models, $R^{2}$ values are about $80.47 \%$ to $85.45 \%$ and $76.82 \%$ to $86.32 \%$ for residential and commercial area, respectively. This confirms variables influence differently PD and OPD in each season and area. Key drivers for PD and OPD are found different under certain seasons for both areas. For $C D D$, $H D D$, and humidity $R H D$, these variables influence relatively stronger seasonal PD and OPD for residential than for commercial area, and likewise effect of holidays $D H$ to the demands. Meanwhile, wind speed WDS tends not to have significance to observed demands. It is hoped, presented information useful for utilities in managing power systems more effective particularly to meet seasonal PD (and OPD) from different areas in one place.

\section{References}

[1] A. Pardo, V. Meneu and E. Valor, "Temperature and Seasonality Influences on Spanish Electricity Load," Energy Economics, Vol. 24, pp. 55-70, 2002.

[2] I. S. Qamber, "Peak Load Modeling for Kingdom of Bahrain", Journal of Software Engineering and Applications, Vol. 5, No. 12B, pp. 46-49, 2012.

[3] J. C. Lam, H. L. Tang, and D. H. W. Li, "Seasonal Variations in Residential and Commercial Sector Electricity Consumption in Hong Kong”, Energy, Vol. 33, pp. 513-523, 2008.

[4] K. Wangpattarapong, S. Maneewan, N. Ketjoy and W. Rakwichian, "The Impacts of Climatic and Economic Factors on Residential Electricity Consumption of Bangkok Metropolis,” Energy and Buildings, Vol. 40, pp. 1419-1425, 2008.

[5] S. Mirasgedis, Y. Sarafidis, E. Georgopoulou, D. P. Lalas, M. Moschovits, F. Karagiannis and D. Papakonstantinou, "Models for Mid-Term Electricity Demand Forecasting Incorporating Weather Influences," Energy, Vol. 31, pp. 208-227, 2006.

[6] S. R. Deeba, and Nahid-Al-Masood, "Correlation between Reliability and Weather Scenario: In Perspective of Bangladesh Power System", International Journal of Energy and Power Engineering, Vol. 2, No. 3, pp. 109-113, 2013.

[7] S. B. Sadineni, and R. F. Boehm, "Measurements and Simulations for Peak Electrical Load Reduction in Cooling Dominated Climate”, Energy, Vol. 37, pp. 689-697, 2012.

[8] Y. S. Akil, and H. Miyauchi, "Seasonal Peak Electricity Demand Characteristics: Japan Case Study", International Journal of Energy and Power Engineering, Vol. 2, No. 3, pp. 136-142, 2013.

[9] B. E. Psiloglou, C. Giannakopoulos, S. Majithia and M. Petrakis, "Factors Affecting Electricity Demand in Athens, Greece and London, UK: A Comparative Assessment," Energy, Vol. 34, pp. 1855-1863, 2009.

[10] Japan Meteorological Agency (JMA). http://www.jma.go.jp/jma/indexe.html

[11] R. Startz, EViews Illustrated for Version 6, 1st Ed., Quantitative Micro Software, LLC, 2007.

[12] EViews. http://www.eviews.com 